\title{
A SELDI mass spectrometry study of experimental autoimmune encephalomyelitis: sample preparation, reproducibility, and differential protein expression patterns
}

Sausan Azzam ${ }^{1}$, Laurie Broadwater ${ }^{1}$, Shuo Li $^{1}$, Ernest J Freeman ${ }^{2}$, Jennifer McDonough ${ }^{2}$ and Roger B Gregory ${ }^{{ }^{*}}$

\begin{abstract}
Background: Experimental autoimmune encephalomyelitis (EAE) is an autoimmune, inflammatory disease of the central nervous system that is widely used as a model of multiple sclerosis (MS). Mitochondrial dysfunction appears to play a role in the development of neuropathology in MS and may also play a role in disease pathology in EAE. Here, surface enhanced laser desorption ionization mass spectrometry (SELDI-MS) has been employed to obtain protein expression profiles from mitochondrially enriched fractions derived from EAE and control mouse brain. To gain insight into experimental variation, the reproducibility of sub-cellular fractionation, anion exchange fractionation as well as spot-to-spot and chip-to-chip variation using pooled samples from brain tissue was examined.
\end{abstract}

Results: Variability of SELDI mass spectral peak intensities indicates a coefficient of variation (CV) of 15.6\% and $17.6 \%$ between spots on a given chip and between different chips, respectively. Thinly slicing tissue prior to homogenization with a rotor homogenizer showed better reproducibility (CV $=17.0 \%)$ than homogenization of blocks of brain tissue with a Teflon ${ }^{\circledR}$ pestle $(C V=27.0 \%)$. Fractionation of proteins with anion exchange beads prior to SELDI-MS analysis gave overall CV values from $16.1 \%$ to $18.6 \%$. SELDI mass spectra of mitochondrial fractions obtained from brain tissue from EAE mice and controls displayed 39 differentially expressed proteins ( $p \leq 0.05)$ out of a total of 241 protein peaks observed in anion exchange fractions. Hierarchical clustering analysis showed that protein fractions from EAE animals with severe disability clearly segregated from controls. Several components of electron transport chain complexes (cytochrome c oxidase subunit 6b1, subunit 6C, and subunit 4; NADH dehydrogenase flavoprotein 3, alpha subcomplex subunit 2, Fe-S protein 4, and Fe-S protein 6; and ATP synthase subunit e) were identified as possible differentially expressed proteins. Myelin Basic Protein isoform 8 (MBP8) $(14.2 \mathrm{kDa})$ levels were lower in EAE samples with advanced disease relative to controls, while an MBP fragment (12. $4 \mathrm{kDa}$ ), likely due to calpain digestion, was increased in EAE relative to controls. The appearance of MBP in mitochondrially enriched fractions is due to tissue freezing and storage, as MBP was not found associated with mitochondria obtained from fresh tissue.

(Continued on next page)

\footnotetext{
* Correspondence: rgregory@kent.edu

'Department of Chemistry and Biochemistry, Kent State University, Kent,

Ohio 44242, USA

Full list of author information is available at the end of the article
} 
(Continued from previous page)

Conclusions: SELDI mass spectrometry can be employed to explore the proteome of a complex tissue (brain) and obtain protein profiles of differentially expressed proteins from protein fractions. Appropriate homogenization protocols and protein fractionation using anion exchange beads can be employed to reduce sample complexity without introducing significant additional variation into the SELDI mass spectra beyond that inherent in the SELDI- MS method itself. SELDI-MS coupled with principal component analysis and hierarchical cluster analysis provides protein patterns that can clearly distinguish the disease state from controls. However, identification of individual differentially expressed proteins requires a separate purification of the proteins of interest by polyacrylamide electrophoresis prior to trypsin digestion and peptide mass fingerprint analysis, and unambiguous identification of differentially expressed proteins can be difficult if protein bands consist of several proteins with similar molecular weights.

\section{Background}

Multiple sclerosis (MS) is an inflammatory neurodegenerative disease of the central nervous system (CNS) characterized by demyelination, oligodendrocyte loss, axonal damage and neurodegeneration which results in progressive physical and cognitive disability [1]. Experimental autoimmune encephalomyelitis (EAE) is an autoimmune, inflammatory disease of the central nervous system that mimics many of the clinical and histological features of MS, including the presence of cellular infiltrates as well as demyelination and axonal degeneration in the CNS [2,3]. As a result, EAE has been widely employed as a model for studying the pathogenesis of MS and for the development of therapeutic approaches to treat the disease [4-8]. There is much interest in the role of oxidative stress and mitochondrial dysfunction in human disease including cardiovascular disease and neurodegenerative diseases [9-12]. A number of studies implicate mitochondrial dysfunction in the development of neuropathology in MS. Decreases in the neuronal mitochondrial metabolite $\mathrm{N}$-acetyl aspartate (NAA) in MS brain have been observed by nuclear magnetic resonance spectroscopy and a decrease in NAA appears to precede neuronal atrophy, suggesting that mitochondrial dysfunction may precede neurodegeneration $[13,14]$. Alterations to mitochondrial enzyme activity and damage to mitochondrial DNA have been observed in MS white matter lesions [16-20]. In addition, defects in mitochondrial electron transport gene expression and function in normal appearing gray matter (NAGM) in postmortem MS cortex have been reported [21,22]. Mitochondrial dysfunction may also play a role in disease pathology in EAE. Increased nitration of components of the electron transport chain leads to decreased mitochondrial activity in EAE [15].

Proteomic profiling has been successfully employed in the discovery and identification of biomarkers in neurodegenerative diseases $[23,24]$ and in the analysis of mitochondrial proteomes in disease [12]. A number of studies utilizing proteomic approaches to investigate the differentially expressed proteins in MS and EAE have been reported [25-33]. Proteomic profiling is a rapidly developing technology that may provide clues to the mechanisms underlying the onset and progression of these diseases. A variety of approaches are available for the analysis of proteomes, including 2D polyacrylamide gel electrophoresis (2D-PAGE) and Differential Gel Electrophoresis (DIGE) [34-36], liquid chromatography coupled to high resolution mass spectrometry (LC-MS), where label-free [37] as well as ICAT [38] and iTRAQ [39] labeling strategies are available for quantitative work and differential analysis [40], and Surface Enhanced Laser Desorption/Ionization Mass Spectrometry (SELDIMS) [41-44].

SELDI-MS was originally developed for rapid, high throughput biomarker discovery in biological fluids (plasma, serum, urine, cerebrospinal fluid) but has been employed to examine the proteomes of cell lysates and tissues $[43,45]$. The approach combines time-of-flight mass spectrometry with protein capture using a variety of chromatographic protein chip surfaces (anion and cation exchange, normal phase, reverse phase, and immobilized metal ion) as well as chemistries for covalent attachment of proteins for affinity capture. It is most sensitive for monitoring low molecular weight $(<20 \mathrm{kDa})$ proteins and peptides. Complex protein samples may also be fractionated (i.e. fractionation on anion exchange beads) prior to spotting protein chips in order to reduce the complexity of SELDI mass spectra. SELDIMS Expression Difference Mapping allows rapid analysis of multiple samples over multiple conditions to identify differentially expressed proteins. Principal component analysis (PCA) and hierarchical clustering can also be employed to identify the mass spectral peaks that distinguish disease from controls [46-51]. Reproducibility in various proteome profiling technologies, including SELDI-TOF mass spectrometry, has been a major challenge. Sources of variability intrinsic to the SELDI-MS technique include variation in the ionization and desorption processes and in time-of-flight measurement and 
ion detection. Errors also can be introduced in mass spectral preprocessing steps such as baseline correction, normalization, and mass spectra alignment. Attempts to reduce proteome complexity and enhance protein identification by the use of sample fractionation steps, including sub-cellular and anion exchange fractionation, can also introduce variability from sample to sample.

In this study, we used SELDI-TOF-MS to obtain protein profiles from mitochondrially-enriched fractions derived from EAE and control mouse brain. To gain insight into sources of experimental variability, we examined the reproducibility of sub-cellular fractionation, anion exchange fractionation as well as spot-to-spot and chip-to-chip variation using pooled samples from brain tissue.

\section{Results}

\section{Spot-to-spot and chip-to-chip variability}

In order to obtain a measure of the reproducibility of the SELDI mass spectral analysis, equal volumes $(1.0 \mu \mathrm{L})$ of anion exchange fraction Q1 from the cytosolic fraction of pooled mouse brain tissue was spotted onto four NP20 protein chips (eight spots per chip) allowing an analysis of both spot-to-spot variation within a chip as well as chip-to-chip variation. The SELDI-MS spectra of each spot (A-H) obtained for one NP20 protein chip is shown in Figure 1. A total of eighteen peaks with signal/ noise $(\mathrm{S} / \mathrm{N})>5$ were found to be common to all spectra measured on this chip which represented proteins with $\mathrm{m} / \mathrm{z}$ ratios in the range from 7,500 to $42,772 \mathrm{Da}$. All spectra have very similar peak patterns as expected for replicates from the same pooled sample. Sources of variability include variation in manually spotting proteins on the chip, the reproducibility of the manufactured spot surfaces, and the intrinsic variation in the ionization and desorption process and in ion time-of-flight and detection. The coefficient of variation for each peak is listed in Table 1. The overall coefficient of variation for the peak intensity for this protein chip was $17.3 \%$. No significant differences in the variability of peak intensities were observed as a function of mass/charge ratio. Analysis of the other three NP20 chips gave similar results with overall coefficients of variation for the peak intensities of $13.6 \%, 16.1 \%$, and $15.3 \%$, suggesting an average coefficient of variation for spot-to-spot variability of $15.6 \%$. A similar analysis of the chip-to-chip variability of peak intensities suggests a slightly larger overall coefficient of variation of $17.6 \%$. These values are similar to

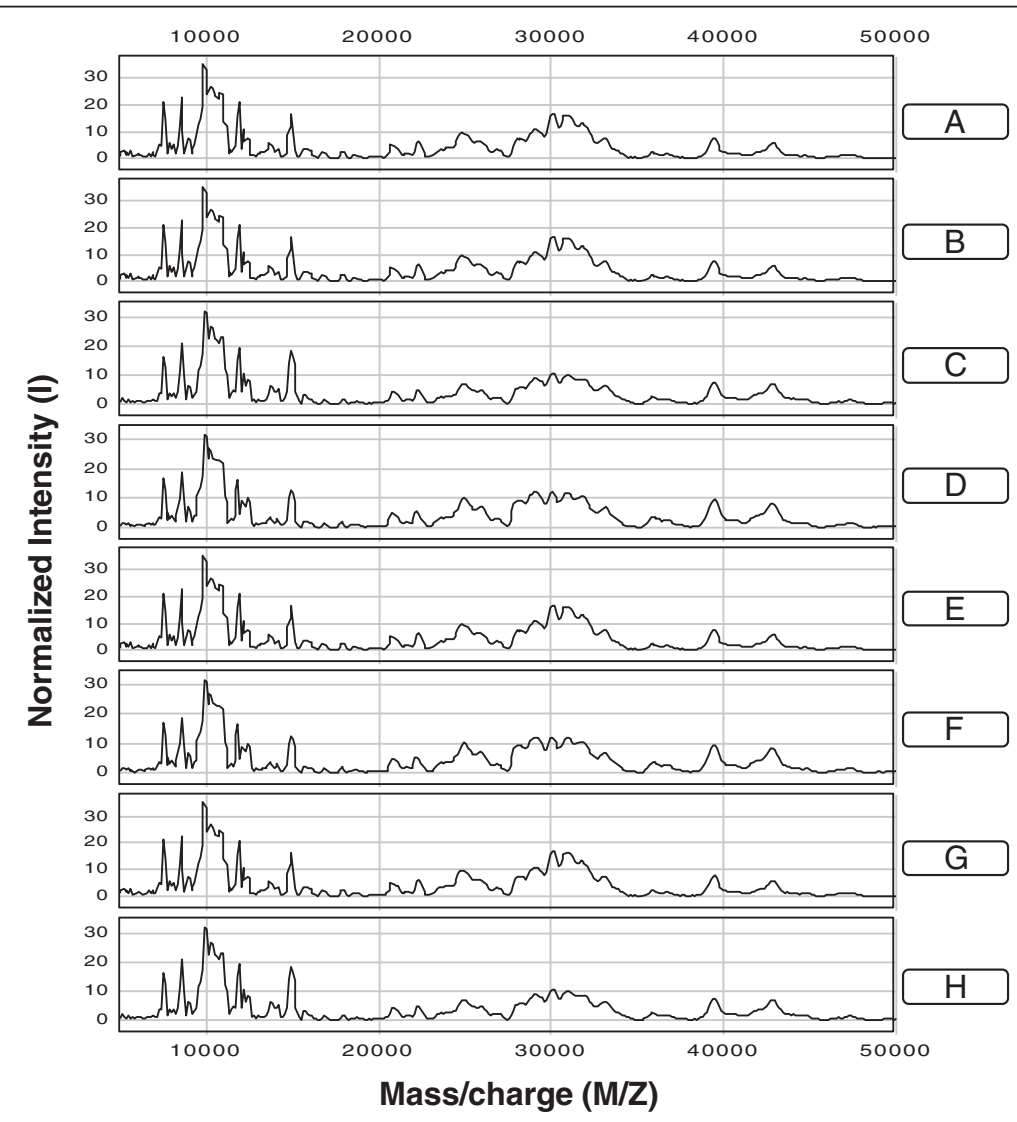

Figure 1 Reproducibility of SELDI-TOF-MS spectra. Examples of SELDI mass spectra obtained for samples of anion exchange fraction Q1 from the cytosolic fraction of pooled mouse brain tissue spotted in eight replicates (A-H) onto an NP20 Protein Chip. 
Table 1 Spot-to-spot variability of SELDI-TOF mass spectra

\begin{tabular}{ccccccc}
\hline \multicolumn{5}{c}{ Peak Intensity } & \multicolumn{3}{c}{ Peak M/Z } \\
\hline Peak & Mean & STD & CV\% & Mean & STD & CV\% \\
1 & 16.0 & 2.4 & 15.3 & 7496.3 & 2.6 & 0.03 \\
2 & 18.5 & 3.2 & 17.1 & 8558.0 & 2.3 & 0.03 \\
3 & 28.5 & 3.9 & 14.0 & 9900.3 & 3.3 & 0.03 \\
4 & 21.2 & 5.8 & 27.2 & 10254.0 & 1.9 & 0.02 \\
5 & 20.8 & 2.7 & 13.2 & 10860.5 & 2.6 & 0.02 \\
6 & 16.8 & 4.1 & 24.7 & 11819.5 & 3.6 & 0.03 \\
7 & 10.9 & 3.2 & 29.5 & 12120.4 & 3.9 & 0.03 \\
8 & 9.1 & 1.8 & 20.2 & 12360.3 & 3.8 & 0.03 \\
9 & 4.1 & 0.6 & 13.8 & 20791.1 & 16.9 & 0.08 \\
10 & 4.8 & 0.6 & 12.5 & 22253.6 & 16.3 & 0.07 \\
11 & 7.4 & 1.3 & 17.4 & 24904.4 & 18.0 & 0.07 \\
12 & 6.0 & 1.5 & 24.8 & 28150.4 & 18.0 & 0.07 \\
13 & 9.1 & 1.0 & 11.5 & 29033.2 & 25.3 & 0.09 \\
14 & 12.0 & 2.1 & 17.7 & 30038.2 & 11.6 & 0.04 \\
15 & 11.6 & 2.1 & 17.9 & 30893.0 & 9.2 & 0.03 \\
16 & 6.3 & 0.6 & 10.1 & 33025.8 & 24.7 & 0.07 \\
17 & 6.8 & 0.7 & 10.0 & 39397.1 & 21.8 & 0.06 \\
18 & 6.0 & 0.8 & 13.9 & 42781.4 & 20.9 & 0.05 \\
\hline
\end{tabular}

The mean, standard deviation, and coefficient of variation (CV\%) for eighteen protein peaks from an ion exchange fraction (Q1) of the cytosolic fraction of pooled mouse brain tissue. The overall $\mathrm{CV} \%$ for peak intensity and $\mathrm{m} / \mathrm{z}$ ratio on this chip were $17.3 \%$ and $0.05 \%$, respectively.

those reported by others for analyses performed on single machines [52-54].

\section{Reproducibility of homogenization and subcellular fractionation protocols}

Depletion of high abundance proteins and fractionation of samples to reduce proteome complexity prior to SELDI-TOF MS analysis can increase the number of detected peaks but can introduce additional variability into the analysis beyond that associated with the SELDI MS method itself $[55,56]$. In order to focus on possible differences in the mitochondrial proteome, to reduce the proteome complexity of brain tissue, and increase the number of detected peaks, particularly for low abundance proteins, we employed sub-cellular fractionation as well as anion exchange fractionation. Our recent work on the proteomics of Multiple Sclerosis has focused on changes occurring in normal appearing grey matter (NAGM) rather than in whole brain or white matter tissue that might include lesions. This type of analysis requires a tissue preparation protocol in which brain tissue is cut into thin slices and the slices flanking the tissue to be homogenized are examined under a microscope to confirm the absence of lesions prior to homogenization.
We have therefore compared the reproducibility of two homogenization methods: method M1, in which tissue was thinly sliced $(60 \mu \mathrm{m}, \sim 250 \mathrm{mg})$ prior to homogenization with a rotor homogenizer (Brinkmann blender), and method M2, in which blocks ( 250 mg) of brain tissue were cut and homogenized with a mechanical homogenizer (Teflon ${ }^{\circledR}$ pestle). To conduct the analysis, pooled mouse brain tissue $(n=6)$ was fractionated into enriched nuclear, cytosolic, and mitochondrial fractions. Three trials were conducted for each homogenization method.

The cytosolic fraction was spotted as four replicates onto NP20 chips. Examples of SELDI mass spectra for the cytosolic Q1 fraction from each trial obtained with the two homogenization methods are shown in Figure 2. Fourteen peaks with $\mathrm{S} / \mathrm{N}>5$ were found to be common to all mass spectra analyzed across the two homogenization protocols and represent proteins with mass/ charge ratios from 7,492 $\mathrm{Da}$ to $42,764 \mathrm{Da}$. The coefficients of variation for each peak are listed in Table 2 and varied from $8.2 \%$ to as much as $60.7 \%$. Overall, homogenization method M1, in which tissue was thinly sliced prior to homogenization with a rotor homogenizer, shows better reproducibility than method M2, in which blocks of brain tissue were cut and homogenized with a mechanical homogenizer.

The overall coefficient of variation for method M1 was $17.0 \%$ compared with $27.0 \%$ for method M2.

The two methods gave a similar pattern of protein intensities, and significant differences in mean peak intensities with the two homogenization methods were observed only for one protein peak $(\mathrm{m} / \mathrm{z}=11,814 \mathrm{Da})$. Nevertheless, it is clear that method M2 introduces significant additional variability beyond that contributed by the SELDI-MS method itself, while homogenization method M1 together with the subcellular fractionation method employed here yield highly reproducible protein samples for proteomic analysis.

\section{Reproducibility of anion exchange fractionation}

The use of anion exchange beads to fractionate samples prior to SELDI-MS analysis greatly improves the resulting mass spectra, but the procedure must be highly reproducible in order to avoid differences in protein retention on the beads or release from the beads, which would alter protein profiles of the fractions from sample to sample. To this end, buffer concentrations and $\mathrm{pH}$ must be carefully monitored and, ideally, anion exchange fractionation performed on all samples on the same day, as was the case with this analysis. Anion exchange of cytosolic fractions with BioSepra Q Ceramic HyperD anion exchange beads yielded six fractions (Q1- Q6). Three trials were performed and three fractions (Q1, Q2, and Q4) from each trial were spotted in triplicate 

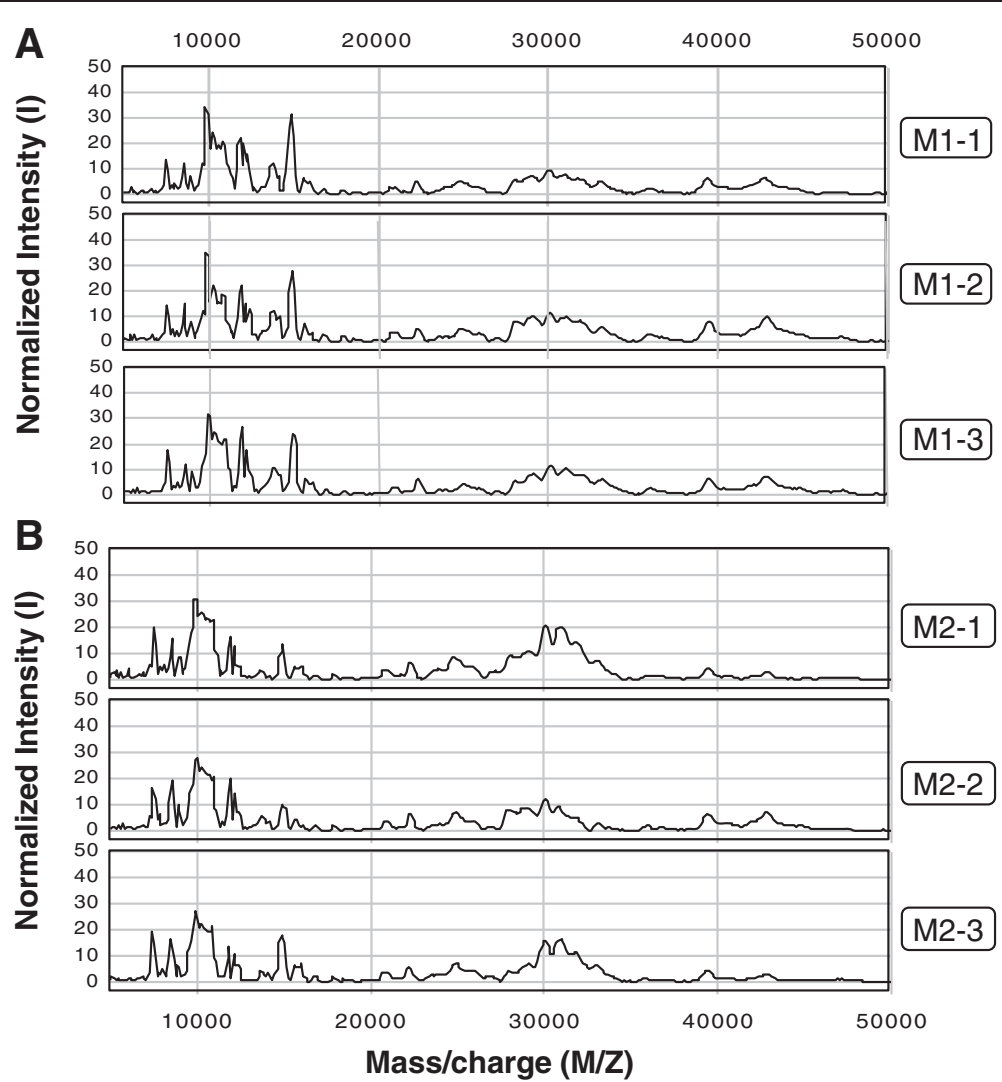

Figure 2 Reproducibility of subcellular fractionation. Examples of SELDI mass spectra obtained for three replicates of the anion exchange fraction Q1 from the cytosolic fraction of pooled mouse cytosolic homogenized using method M1 (top) and method M2 (bottom).

onto NP20 protein chips. Seven peaks with $\mathrm{S} / \mathrm{N}>5$ were found that were common to all SELDI mass spectra of fraction Q1. The overall coefficient of variation for the peak intensities was $16.1 \%$. Analyses of fraction Q2, with 11 peaks common to all spectra, and Q4, with 8 peaks common to all spectra, gave overall coefficients of variation of $18.6 \%$ and $17.3 \%$ for peak intensity, respectively.

These results suggest that anion exchange prefractionation can be performed reproducibly and does not introduce significant additional variation to the SELDI mass spectra beyond that inherent in the SELDIMS method itself, which is comparable to the variability reported by other SELDI-MS users [52,54].

\section{EAE protein expression profiles}

The clinical appearance of EAE is of an ascending myelitis, the severity of which is scored on a scale from 0 (normal animal) to 5 (moribund state). SELDI mass spectra were determined for mitochondrial fractions obtained from brain tissue from one mouse (labeled E1) at EAE disease stage 1 (animals display tail paralysis with mild meningeal inflammation), and four mice (labeled E2 - E5) at EAE disease stage 3 (animals display complete paralysis of one or both hind limbs with severe meningitis, and parenchyma infiltration with multiple perivascular infiltration), as well as from brain tissue from three controls (labeled C1 - C3). The mitochondrial subcellular fractions were further fractionated on anion exchange beads to give six fractions (Q1- Q6) for SELDI-MS analysis. A total of 241 protein peaks (clusters) were identified in these six fractions which met our selection criteria. A total of 39 protein peaks were found to be differentially expressed ( $\mathrm{p} \leq 0.05$ ) (see Table 3 ). Eleven proteins were found at greater levels in EAE brains relative to controls and 28 proteins were found at lower levels in EAE brains relative to controls. As shown in Table 3, the differentially expressed proteins are seen in all six anion exchange fractions (Q1-Q6) and include proteins with mass/charge ratios from 3,006 to 49,085 Da. This represents a large fraction (16\%) of the observed peaks, and it is possible that some proteins have been counted twice (i.e. they are observed under both the LMW and HMW acquisition conditions employed here), for example, the protein peaks at mass/charge ratios of 13,365 (HMW) and 13,331 (LMW) in fraction Q2; 12,448 (HMW) and 12,493 (LMW) in fraction Q3; 16,910 (HMW) and 16,878 (LMW) in fraction Q5; and 
Table 2 Reproducibility of homogenization and subcellular fractionation protocols

\begin{tabular}{ccc}
\hline M/Z & M1 & M2 \\
\hline 7487 & CV\% & CV\% \\
10854 & 16.8 & 20.1 \\
11814 & 20.0 & 16.2 \\
12106 & 8.2 & 20.5 \\
15615 & 23.1 & 42.7 \\
20758 & 45.4 & 60.7 \\
24905 & 8.5 & 18.7 \\
28979 & 14.7 & 38.4 \\
30002 & 11.4 & 17.0 \\
30818 & 14.0 & 32.3 \\
31718 & 8.6 & 35.5 \\
33018 & 20.2 & 27.0 \\
39336 & 28.3 & 19.5 \\
42760 & 8.9 & 7.1 \\
Overall CV\% & 10.0 & 22.1 \\
\hline
\end{tabular}

The coefficient of variation (CV\%) for fourteen protein peaks from an ion exchange fraction (Q1) of the cytosolic fraction of pooled mouse brain tissue obtained for two homogenization protocols in which tissue was either thinly sliced prior to homogenization with a Brinkmann rotor homogenizer (method M1) or tissue was cut into $\sim 250 \mathrm{mg}$ blocks and homogenized with a Teflon pestle (method M2). The overall CV\% for the peak intensities was $17.0 \%$ for method $\mathrm{M} 1$ and $27 \%$ for method M2.

13,854 (HMW) and 13,809 (LMW) in fraction Q6. In addition, some peaks with different $\mathrm{m} / \mathrm{z}$ ratios may represent proteolytic fragments of the same protein.

Protein expression profiles were further analyzed with hierarchical clustering techniques [49] and principal component analysis (PCA) $[46,47,57]$. Hierarchical clustering of differentially expressed proteins employed a modified Pearson product-moment correlation coefficient as a distance measure and used the average linkage method to compute dendrograms in which the nodes join "objects" (protein fractions) with the most similar protein expression profiles. The relative length of the branches indicates the similarity of the expression profiles.

The result of a hierarchical clustering analysis of fraction Q3 obtained with a HMW data acquisition protocol is given in Figure $3 \mathrm{C}$ and shows that the protein fractions are segregated into two distinct groups: (EAE stage 3 ) and (controls + EAE stage 1). This clustering of the EAE disease stage 1 sample with controls was also observed with fraction Q2 (Figure 4B). However, the segregation of EAE disease stage 1 with controls may not be significant as only one sample at this disease stage was examined.

Principal component analysis allows us to explore patterns and identify the most important sources of variation in large datasets. Principal component analysis computes a set of orthogonal directions called principal components. The first principal component is the eigenvector of the covariance matrix which has the largest eigenvalue and accounts for the greatest variation in the data. The second principal component (i.e. with the next largest eigenvalue) is the eigenvector, orthogonal to the first principal component, which accounts for the next most variance, and so on. The contribution of each principal component to a particular protein expression profile is given by the principal component score. The first several principal components often account for much of the variability in the data and indicate which features most contribute to this variability, while the principal component scores relate that variability to each sample.

As a result, the essential features of the data can often be captured in a model of much smaller dimensionality than the original dataset. In the case of the Q3 HMW dataset, the first three principal components account for $\sim 84 \%$ of the variability in the data. A scatter plot (Figure 3B) of the scores for principal components 1 and 2 clearly shows the segregation of the dataset into EAE and control samples. Analysis of other fractions shows a similar behavior. For example, the scatter plot of scores for principal components 1 and 2 obtained from a Principal Component Analysis of fraction Q6 with a LMW acquisition protocol (Figure 5) also shows a clear segregation of EAE and control samples. Hierarchical clustering analysis can help identify interesting correlations among peaks. For example, the lowest node in the dendrogram for fraction Q6 LMW consists of five highly correlated peaks at 3006, 3040, 3266, 4020, and $4272 \mathrm{Da}$ suggesting a strong relationship between the peaks. Three of them are differentially expressed with $p$ values of 0.03. Without further analysis, the basis of this correlation cannot be determined, but strongly correlated peaks in this mass range could reflect proteolytic fragments of the same protein, the expression of a set of related proteins in response to a stimulus, or posttranslationally modified species.

Principal component analysis of fraction Q2 with a LMW acquisition protocol (Figure 4) shows a clear discrimination of EAE stage 3 samples from controls + EAE stage 1 samples. Hierarchical clustering analysis also clusters the EAE stage 1 (E1) sample with controls rather with the more advanced EAE disease samples (E2 - E5). The possibility that some protein fractions might be able to discriminate early from advanced EAE disease is interesting. However, with only one early stage EAE sample, this clustering may not be significant. In all cases, the first three principal components account for most $(>80 \%)$ of the variation in the data, indicating that much of the structure in the dataset can be represented by a relatively low dimensionality analysis. 
Table 3 Differentially expressed protein peaks in EAE as compared to control brain tissue

\begin{tabular}{|c|c|c|c|c|c|}
\hline Fraction (Q) & Mass $(\mathrm{m} / \mathrm{z})$ & Acquisition settings & p-Value & ROC Area & Expression change in $\mathrm{EAE}$ \\
\hline 1 & 108995 & $\mathrm{HMW}$ & 0.03 & 0.00 & $\downarrow$ \\
\hline 2 & 6540 & HMW & 0.05 & 0.13 & $\downarrow$ \\
\hline 2 & 10274 & HMW & 0.05 & 0.07 & $\downarrow$ \\
\hline 2 & 11691 & HMW & 0.05 & 1.00 & $\uparrow$ \\
\hline 2 & 13365 & HMW & 0.05 & 0.07 & $\downarrow$ \\
\hline 2 & 14349 & HMW & 0.05 & 1.00 & $\uparrow$ \\
\hline 2 & 16836 & HMW & 0.05 & 0.00 & $\downarrow$ \\
\hline 2 & 31521 & HMW & 0.05 & 0.07 & $\downarrow$ \\
\hline 2 & 13331 & LMW & 0.03 & 0.00 & $\downarrow$ \\
\hline 2 & 49085 & LMW & 0.05 & 0.06 & $\downarrow$ \\
\hline 3 & 8044 & HMW & 0.02 & 0.00 & $\downarrow$ \\
\hline 3 & 10416 & HMW & 0.03 & 0.07 & $\downarrow$ \\
\hline 3 & 10862 & HMW & 0.02 & 0.00 & $\uparrow$ \\
\hline 3 & 12448 & HMW & 0.05 & 0.96 & $\uparrow$ \\
\hline 3 & 13954 & HMW & 0.05 & 0.03 & $\downarrow$ \\
\hline 3 & 8251 & LMW & 0.05 & 0.00 & $\downarrow$ \\
\hline 3 & 10855 & LMW & 0.03 & 0.00 & $\downarrow$ \\
\hline 3 & 12493 & LMW & 0.05 & 0.95 & $\uparrow$ \\
\hline 3 & 15498 & LMW & 0.03 & 0.00 & $\downarrow$ \\
\hline 4 & 9841 & HMW & 0.03 & 1.00 & $\uparrow$ \\
\hline 4 & 42924 & HMW & 0.05 & 0.93 & $\uparrow$ \\
\hline 4 & 6583 & LMW & 0.05 & 0.07 & $\downarrow$ \\
\hline 4 & 9115 & LMW & 0.05 & 0.07 & $\downarrow$ \\
\hline 5 & 8528 & HMW & 0.02 & 0.00 & $\downarrow$ \\
\hline 5 & 16910 & HMW & 0.02 & 0.00 & $\downarrow$ \\
\hline 5 & 17307 & HMW & 0.02 & 0.00 & $\downarrow$ \\
\hline 5 & 8392 & LMW & 0.03 & 0.00 & $\downarrow$ \\
\hline 5 & 9801 & LMW & 0.05 & 0.93 & $\uparrow$ \\
\hline 5 & 16878 & LMW & 0.03 & 0.00 & $\downarrow$ \\
\hline 5 & 17280 & LMW & 0.05 & 0.00 & $\downarrow$ \\
\hline 6 & 9717 & HMW & 0.03 & 0.00 & $\downarrow$ \\
\hline 6 & 13854 & HMW & 0.03 & 1.00 & $\uparrow$ \\
\hline 6 & 3006 & LMW & 0.03 & 0.00 & $\downarrow$ \\
\hline 6 & 3266 & LMW & 0.03 & 0.00 & $\downarrow$ \\
\hline 6 & 4272 & LMW & 0.03 & 0.00 & $\downarrow$ \\
\hline 6 & 5455 & LMW & 0.03 & 0.00 & $\downarrow$ \\
\hline 6 & 10637 & LMW & 0.05 & 0.07 & $\downarrow$ \\
\hline 6 & 13809 & LMW & 0.03 & 1.00 & $\uparrow$ \\
\hline 6 & 23228 & LMW & 0.05 & 0.93 & $\uparrow$ \\
\hline
\end{tabular}




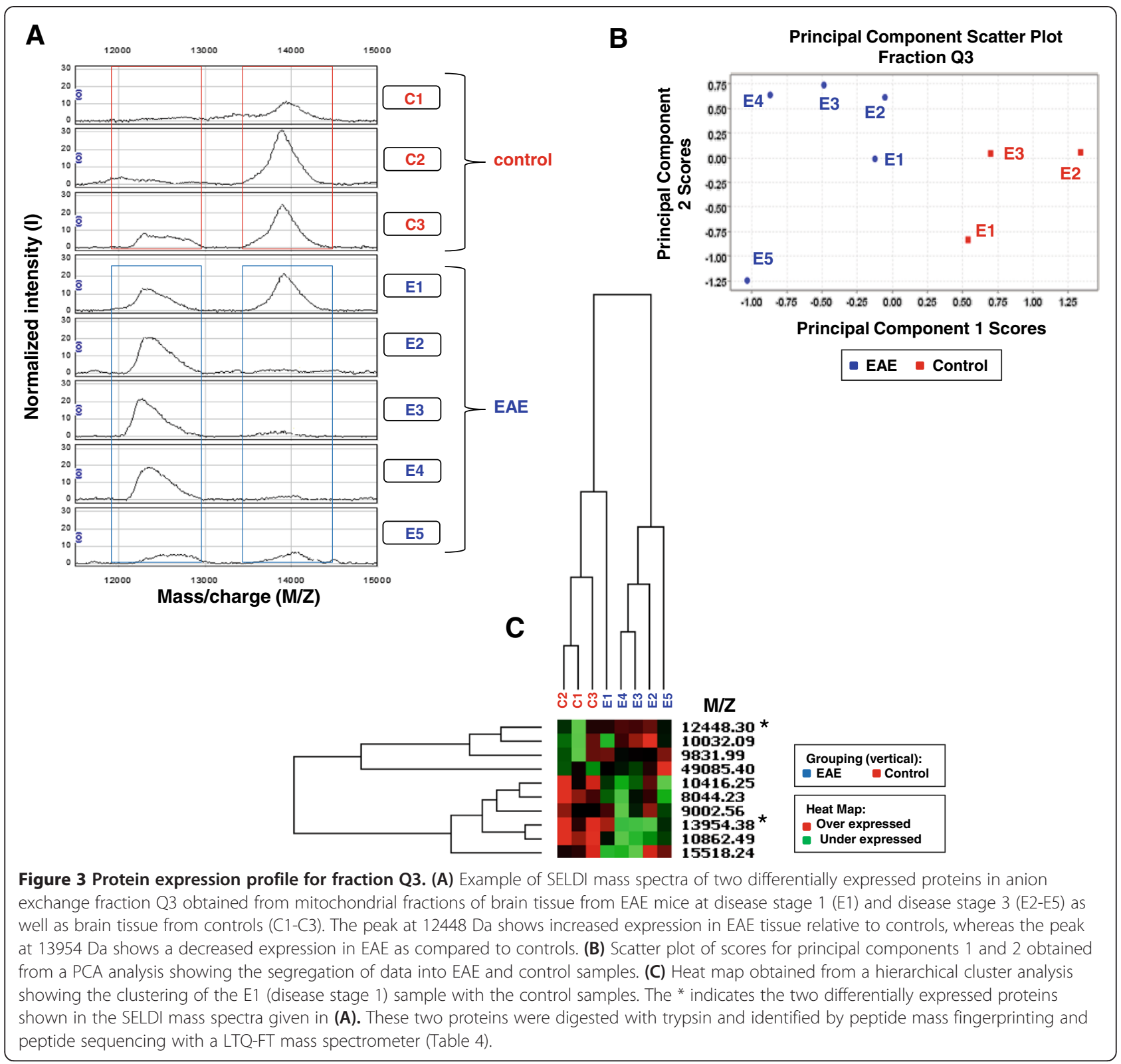

\section{Identification of differentially expressed proteins}

SELDI-MS workflows enable the rapid analysis of a large numbers of protein samples and can generate patterns of differentially expressed proteins that may distinguish disease states from controls. However, protein identification usually requires separate purification of the proteins of interest by polyacrylamide gel electrophoresis prior to trypsin digestion and peptide mass fingerprint analysis, and confirmation of protein identity by Western blotting analysis. Unambiguous identification of differentially expressed proteins can be difficult if protein bands obtained from 1D polyacrylamide gel electrophoresis (PAGE) consist of several proteins with similar molecular weights. However, the subcellular fractionation of the sample into cytosolic, mitochondrial, and nuclear fractions combined with ion exchange fractionation prior to 1D PAGE employed in the current work is actually a multi-dimensional separation, albeit with low resolution fractionations (3 subcellular fractions and 6 ion exchange fractions) for the first two steps, and one might expect more success in resolving individual proteins than with 1D PAGE alone.

Fractions Q2, Q3, Q4, and Q5 from control or EAE brain tissue were subjected to 1D SDS polyacrylamide gel electrophoresis together with SeeBlue Plus 2 prestained molecular weight standards. The gels were stained with Coomassie Brilliant blue R 250 and destained overnight. 


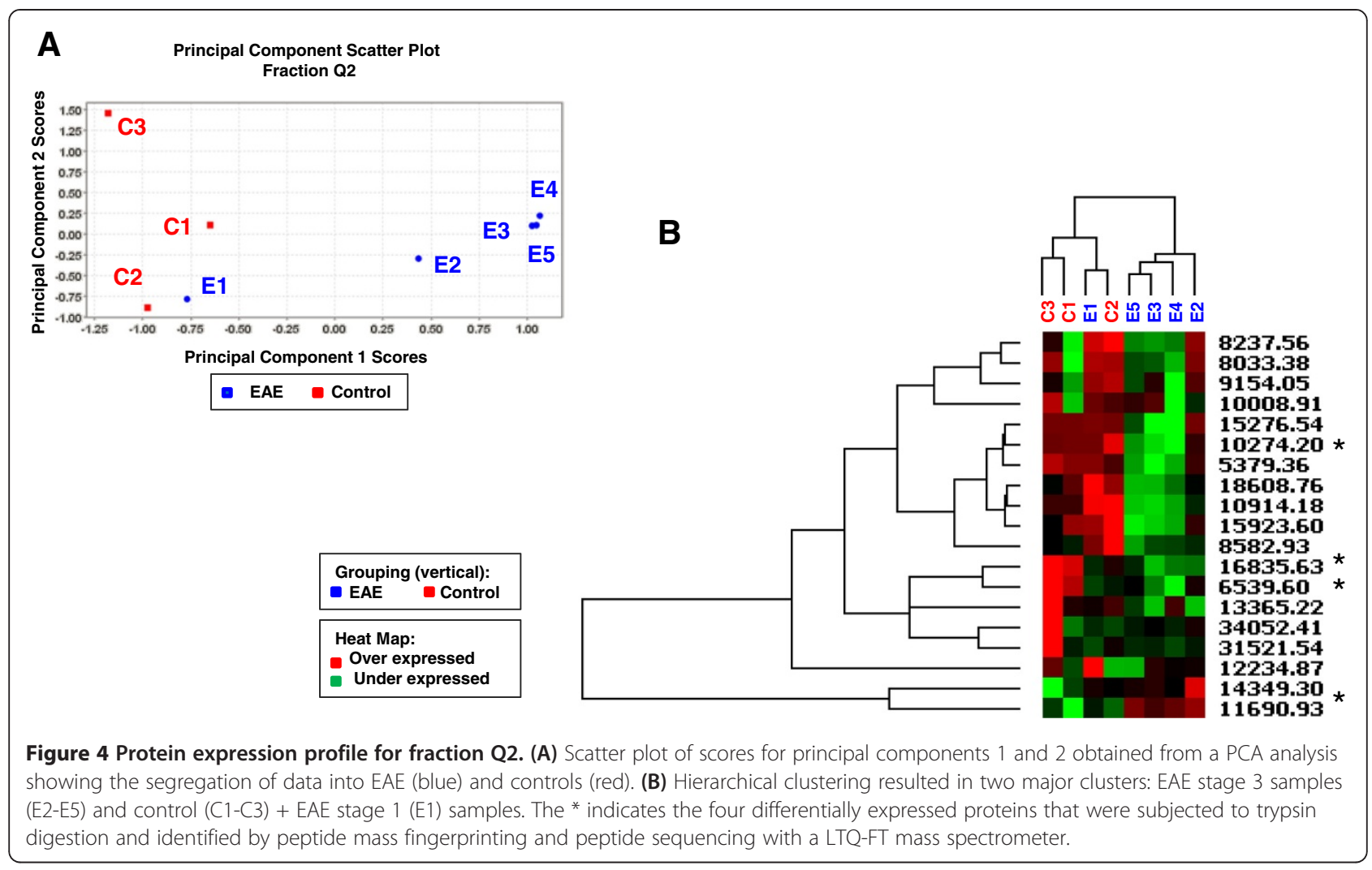

Protein bands corresponding to the molecular weights of differentially expressed proteins of interest were excised and the proteins in the gel plugs were treated with dithiothreitol and iodoacetamide to reduce any disulfide bonds and alkylate the resulting thiol groups. The proteins were digested with trypsin and identified by peptide mass fingerprinting and peptide sequencing with a LTQ-FT mass spectrometer at the Center for Proteomics and Bioinformatics, Case Western Reserve University. The resulting peak list files were used to interrogate the indexed IPI mouse database with the Mascot algorithm. The list of identified proteins is given in Table 4 and is dominated by components of the electron transport chain including cytochrome c oxidase subunit 6b1 (COX6b1), subunit 6C (COX6C), and subunit 4 (COX4i1); NADH dehydrogenase flavoprotein 3 (Ndufv3), alpha subcomplex subunit 2 (Ndufa2), Fe-S protein 4 (Ndufs4), and Fe-S protein 6 (Ndufs6); and ATP synthase subunit e (Atp5k); as well as myelin basic protein isoforms. Other proteins include ubiquitin A-52 protein (Uba52), a protein involved in ion homeostasis; CPN10-like protein Hspe-rs1 (Cpn10rs1), which is a member of the GroES chaperonin family; beta2 microglobulin (B2m); cofilin 1 (Cfl1); V-type proton ATPase subunit G2 (Atp6v1g2), a vacuolar ATPase which mediates the acidification of intracellular compartments; basic transcription factor 3 (btf3) and the 40S ribosomal protein S13 (Rps13). Because the protein bands in fraction Q3 each consist of a single identified protein, the identity of the differentially expressed proteins as myelin basic protein (MBP) isoforms is unambiguous. However, we have not confirmed which of the other proteins identified in gel bands represents the differentially expressed protein peaks observed in SELDI mass spectra. Recent studies have implicated mitochondrial dysfunction as a possible mechanism in the development of neuropathology in MS (13, 14, 21, 22, 31, and 58) and increased levels of nitration among proteins of the electron transport chain result in reduced mitochondrial activity in EAE [59].

The appearance of a number of components of electron transport chain complexes (cytochrome c oxidase subunit 6b1, subunit $6 \mathrm{C}$, and subunit 4; NADH dehydrogenase flavoprotein 3 , alpha subcomplex subunit 2 , Fe-S protein 4, and Fe-S protein 6; and ATP synthase subunit e) among the list of potential differentially expressed proteins is interesting given the identification of cytochrome c oxidase subunit 4 (32), subunit 5a (30), and subunit $5 \mathrm{~b}(30,31)$ as being differentially expressed in $\mathrm{EAE}$ or $\mathrm{MS}$ in previous studies. A recent proteomics study of spinal cord during the clinical course of EAE (33) identified 35 differentially expressed proteins out of 800 spots observed by 2D PAGE, including proteins involved in energy pathways and cell growth, and 


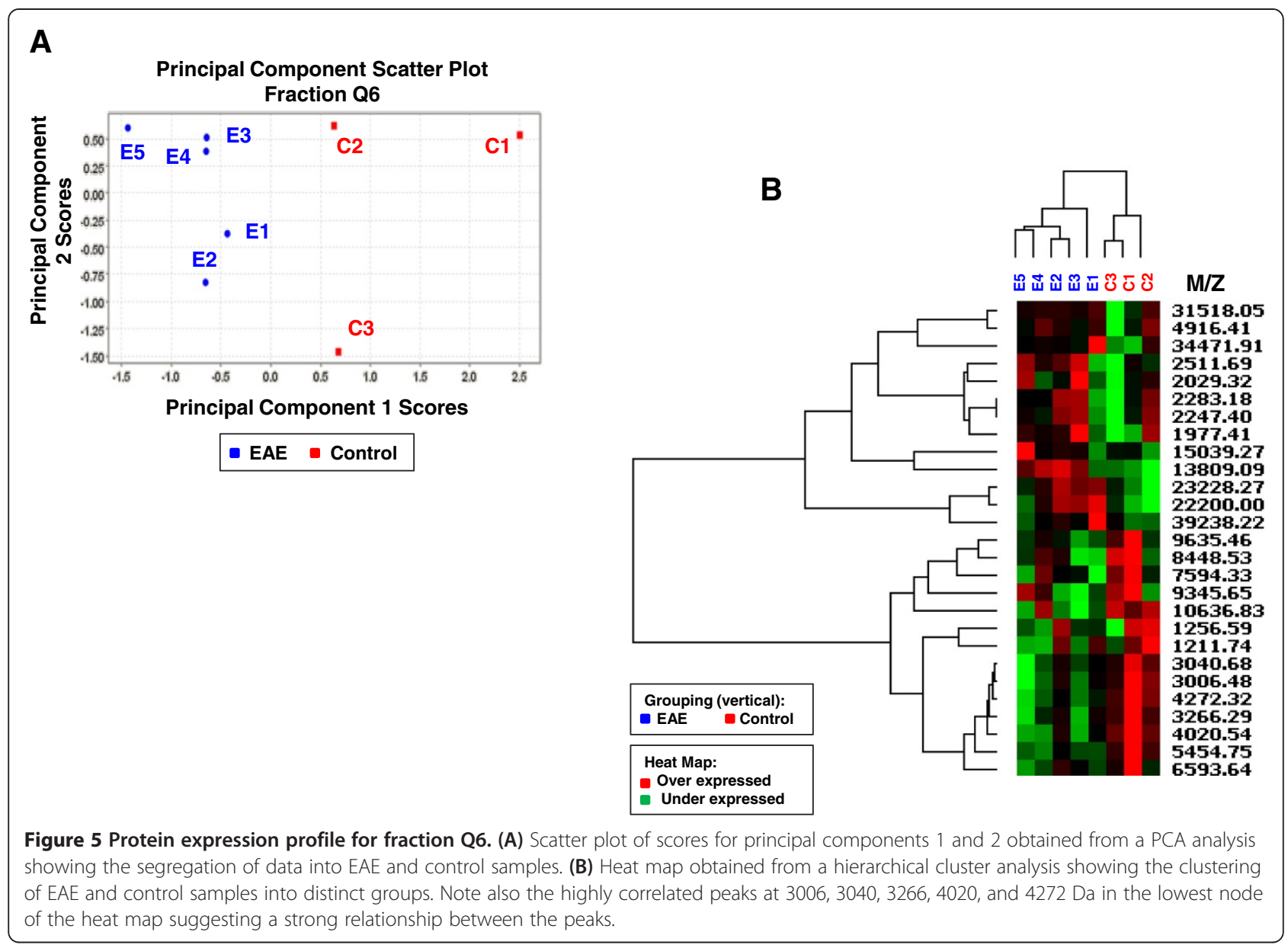

transport processes. Only a few mitochondrial proteins were differentially expressed, and none correspond to the mitochondrial proteins described here. Farias et al (33) found decreased expression of vacuolar ATPase subunit B in EAE relative to controls, while we observe vacuolar ATPase subunit G2 (Atp6v1g2) in differentially expressed band Q5. This V-type proton ATPase mediates the acidification of intracellular compartments.

\section{Myelin basic protein}

The identity of the differentially expressed proteins in fraction Q3 as myelin basic protein isoforms was confirmed with Western blots (not shown). MBP is not expected to be associated with mitochondria. Indeed Ravera et al [60] reported finding no MBP in mitochondria using fresh bovine brain tissue and slightly different preparation conditions. MBP is a basic protein that interacts with membranes and it is possible that the mitochondrially-enriched fraction was contaminated with MBP released from myelin during tissue homogenization. To test this we added fluorescently labeled MBP to brain tissue prior to homogenization and measured the fluorescence intensity of nuclear, mitochondrial and cytoplasmic fractions. Most fluorescence is observed in the cytoplasmic $(70 \%)$ and nuclear $(22 \%)$ fractions, with less than $2 \%$ of the total fluorescence observed in the mitochondrially enriched fraction. While this is only a small fraction of the total MBP added, we cannot rule out contamination of the mitochondrial fraction by free MBP. Freezing and storage are known to lead to contamination of mitochondria by synaptosomal membrane fragments [61] and it is possible that freezing and storage of brain tissue blocks prior to homogenization and subcellular fractionation also leads to contamination of mitochondria by myelin membrane fragments or myelin vesicles. To test this we employed Western blots to determine if contamination was also observed in the mitochondrial fraction obtained with fresh mouse brain tissue. The presence of MBP isoforms in mitochondrial fractions from frozen control and EAE mouse brain tissue was confirmed in a Western blot probed with antibodies to mouse MBP (Figure 6A). The $21.5 \mathrm{kDa}$ MBP isoform was clearly seen in both frozen control and EAE mouse samples. In addition, other MBP isoforms or MBP fragments are observed in the frozen EAE sample. By contrast, no MBP was detected in mitochondrial 
Table 4 Protein identification

\begin{tabular}{|c|c|c|c|c|c|c|c|c|}
\hline $\begin{array}{l}\text { Fraction } \\
(\mathrm{Q})\end{array}$ & $\begin{array}{l}\text { Mass } \\
(\mathrm{m} / \mathrm{z}) \\
\end{array}$ & $\mathrm{p}$-Value & $\begin{array}{c}\text { Accession } \\
\text { number }\end{array}$ & $\begin{array}{l}\text { Entry } \\
\text { name }\end{array}$ & $\begin{array}{c}\text { Theoretical } \\
\text { MW }\end{array}$ & $\begin{array}{c}\text { MASCOT } \\
\text { score }\end{array}$ & $\begin{array}{l}\text { Peptides } \\
\text { detected }\end{array}$ & $\begin{array}{l}\text { Sequence } \\
\text { coverage }\end{array}$ \\
\hline \multirow[t]{9}{*}{2} & 6550 & 0.05 & IPI00138892 & Uba52 & 14719 & 642 & 7 & 46 \\
\hline & & & IPI00225390 & cox6b1 & 10065 & 84 & 2 & 24 \\
\hline & 10274 & 0.05 & IPI00225390 & cox6b1 & 10065 & 545 & 7 & 67 \\
\hline & & & IPI00120045 & Hspe1-rs1 & 10971 & 431 & 3 & 33 \\
\hline & & & IPI00403381 & Ndufv3 & 11806 & 430 & 4 & 36 \\
\hline & 11691 & 0.05 & IPI00109966 & B2m & 13814 & 499 & 4 & 27 \\
\hline & & & IPI00128345 & Ndufs6 & 13012 & 414 & 3 & 31 \\
\hline & 16836 & 0.05 & IPI00890117 & $\mathrm{Cfl} 1$ & 18548 & 663 & 12 & 70 \\
\hline & & & IPI00229008 & Ndufs4 & 19772 & 335 & 8 & 48 \\
\hline \multirow[t]{2}{*}{3} & 12448 & 0.05 & IPI00115240 & MBP1 & 27151 & 443 & 5 & 15 \\
\hline & 13954 & 0.05 & IPI00223381 & MBP8 & 14202 & 584 & 12 & 61 \\
\hline \multirow[t]{5}{*}{4} & 9841 & 0.03 & IPI00131771 & cox6C & 8464 & 1460 & 9 & 63 \\
\hline & & & IPI00223593 & MBP10 & 20801 & 1049 & 11 & 50 \\
\hline & & & IPI00111770 & Atp5k & 8230 & 473 & 7 & 68 \\
\hline & & & IPI00225390 & cox6b1 & 10065 & 443 & 6 & 53 \\
\hline & & & IPI00315302 & Ndufa2 & 10909 & 428 & 5 & 41 \\
\hline \multirow[t]{6}{*}{5} & 16910 & 0.02 & IPI00223379 & MBP6 & 17215 & 2521 & 14 & 64 \\
\hline & & & IPI00123817 & Atp6v1g2 & 13643 & 501 & 4 & 39 \\
\hline & 17307 & 0.02 & IPI00223380 & MBP7 & 17230 & 1168 & 12 & 70 \\
\hline & & & IPI00319231 & Rps13 & 17212 & 362 & 7 & 45 \\
\hline & & & IPI00229008 & Ndufs4 & 19772 & 354 & 8 & 34 \\
\hline & & & IPI00131186 & Btf3 & 17688 & 329 & 3 & 46 \\
\hline
\end{tabular}

Proteins identified in 1D polyacrylamide gel bands which correspond to the molecular weights of differentially expressed proteins in EAE relative to controls found by SELDI-MS analysis. Only the myelin basic protein isoforms found in fraction Q3 are unambiguously identified.

fractions derived from fresh mouse tissue (Figure 6B left lane). The positive control (Figure $6 \mathrm{~B}$ right lane) was prepared by adding purified bovine $18.6 \mathrm{kDa} \mathrm{MBP}$ isoform to the mitochondrial fraction derived from fresh mouse tissue. This gel was probed with both mouse and bovine anti-MBP antibodies.

So it appears that the presence of MBP in the mitochondrial fraction is an artifact of tissue freezing and storage. Nevertheless, differential expression of MBP isoforms and proteolytic fragments appears to be a consistent feature of EAE. Increases in expression of MBP isoforms also have been observed in mitochondriallyenriched fractions from MS brain tissue relative to controls, where the differential expression of MBP was an important factor separating MS samples from controls in principal component analysis [31]. We have identified the peak at $13,954 \mathrm{Da}$, which decreases in EAE relative to controls, as MBP8 (the $14.2 \mathrm{kDa}$ isoform). There is also a peak at $12,448 \mathrm{Da}$, which increases in EAE relative to controls, and is identified as MBP1, the canonical $\mathrm{MBP}$, but in fact, the relatively small number of peptides (five) and sequence coverage (15\%), mean this peak could be any MBP isoform except isoform 3. Its $\mathrm{m} / \mathrm{z}$ ratio is consistent with it being a proteolytic fragment of MBP. The reduction of the 14.2 kDa MBP isoform and the increase in the $12.4 \mathrm{kDa} \mathrm{MBP}$ fragment in EAE animals with stage 3 diseases is clearly evident in the SELDI mass spectra shown in Figure 3A. Proteolysis has long been thought to play a role in multiple sclerosis, and elevated proteolytic activity has been observed in cerebrospinal fluid in MS patients [62]. Several proteases have been implicated in the degradation of myelin proteins and the generation of immunogenic peptides in multiple sclerosis and experimental autoimmune encephalomyelitis (EAE) including calpain, trypsin 4, matrix metalloproteinase, myelencephalon-specific protease (MSP), plasminogen activators and cathepsin D [63-66]. Liu et al. [65] reported fragmentation of MBP following traumatic brain injury, and linked this to the protease calpain with a major cleavage site between Phe-and Lys of the peptide TQDENPVVHFF--K. They reported the degradation of the 21.5 and $18.5 \mathrm{kDa} \mathrm{MBP}$-isoforms into $\mathrm{N}$-terminal fragments of 10 and $8 \mathrm{kDa}$ in the cortex. They also observed a similar degradation of the 17 and $14 \mathrm{kDa}$ MBP-isoforms. Their identification was based on three matching tryptic peptides, two of which, 


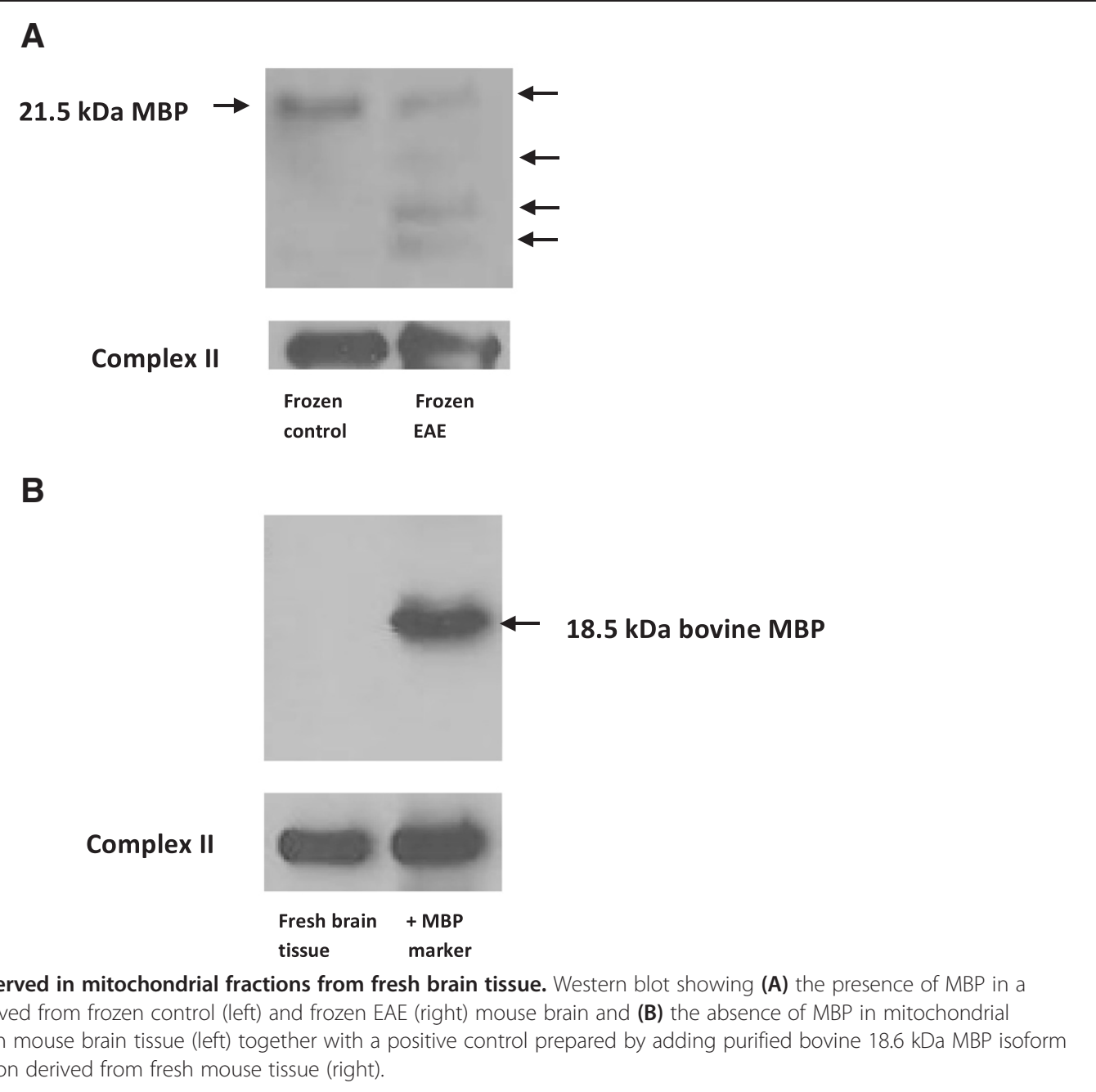

DTGILDSIGR and TQDENPVVHFFK, were observed in our study. Ottens et al. [62] reported significant proteolysis of the $21.5,14.2$, and $18.5 \mathrm{kDa}$ isoforms in a traumatic brain injury model. Six predicted calpain fragments of MBP were described including a $12.6 \mathrm{kDa}$ fragment which may be related to the $12.4 \mathrm{kDa}$ MBP fragment identified in our fraction Q3. Another EAE study [64] showed that the 18.5 and $14.2 \mathrm{kDa}$ MBP isoforms were substantially degraded by calpain to 10 and $11 \mathrm{kDa}$ fragments. Additionally, Matrix metalloproteinases (MMPs) are reported to play a significant role in the fragmentation of MBP and demyelination leading to multiple sclerosis and EAE [58]. The mechanisms of myelin breakdown in MS are not clearly established but degradation of MBP has been thought to be the initial step in the breakdown of myelin in demyelinating diseases. This hypothesis is supported by the degradation and loss of protein from MS plaque believed to be associated with increased activities of the proteolytic enzymes in demyelinating conditions such as MS and EAE.

\section{Conclusions}

We have demonstrated that SELDI mass spectrometry can be employed to explore the proteome of a complex tissue (brain) and have obtained protein profiles of differentially expressed proteins from mitochondrially enriched protein fractions from experimental autoimmune encephalomyelitis (EAE) and control mouse brain. We have shown that appropriate homogenization protocols and protein fractionation using anion exchange beads can be employed to reduce sample complexity without introducing significant additional variation into the SELDI mass spectra beyond that inherent in the SELDI- MS method itself. Overall reproducibility is comparable to that reported by others for analyses performed on a single machine with a coefficient of variation less than 19\%. Although, SELDIMS coupled with principal component analysis and hierarchical cluster analysis provides protein patterns that can clearly distinguish the disease state from controls, the identification of individual differentially expressed proteins requires a separate purification of the proteins of interest 
by polyacrylamide electrophoresis prior to trypsin digestion and peptide mass fingerprint analysis. Unambiguous identification of differentially expressed proteins can be difficult if protein bands consist of several proteins with similar molecular weights. Our multi-dimensional use of subcellular fractionation and ion exchange fractionation prior to 1D PAGE was insufficient to resolve all proteins, although the use of a larger number of ion exchange fractions might have resolved more proteins. We have shown that myelin basic protein isoform 8 (MBP8) $(14.2 \mathrm{kDa})$ levels are lower in EAE samples with advanced disease relative to controls, while an MBP fragment $(12.4 \mathrm{kDa})$, likely due to calpain digestion, is increased in EAE brain tissue relative to controls. Although differential expression of MBP and its proteolytic fragments appears to be a consistent feature of EAE, we have shown that MBP is not found associated with mitochondria obtained from fresh tissue, and instead its appearance in mitochondrially enriched fractions used here is most likely due to tissue freezing and storage.

\section{Methods \\ Materials}

Reagents used for the preparation of all buffers were obtained from Sigma-Aldrich (St. Louis, MO).

\section{Brain tissue samples}

EAE was induced in C57Bl/6 mice by subcutaneous injection of $\mathrm{MOG}_{35-55}$ as previously described [67]. EAE brains from mice at disease stage 1 and 3 and brains from control littermates were prepared at The University of Calgary and sent frozen to Kent State University. The reproducibility study was conducted with pooled tissue from six control mice brains.

\section{Subcellular fractionation of frozen tissue}

Two tissue homogenization methods were tested. In the first method (M1), $60 \mu \mathrm{m}$ tissue slices (approximately 250 $\mathrm{mg}$ ) were cut and a Brinkmann blender was employed to homogenize the tissue. In the second method (M2), small blocks (approximately $250 \mathrm{mg}$ ) of brain tissue were cut and homogenized with a Teflon ${ }^{\circledR}$ pestle homogenizer. For both homogenization methods, frozen brain tissue was suspended in whole cell homogenization buffer $(20 \mathrm{mM}$ $\mathrm{KCl}, 3 \mathrm{mM} \mathrm{MgCl}$, $10 \mathrm{mM}$ 4-(2-hydroxyethyl)-1-piperazine ethanesulfonic acid (HEPES), pH 7.9 0.5\% NP-40, 5\% glycerol, with protease inhibitors (P2714, Sigma-Aldrich, St. Louis, MO)). The cell homogenate was centrifuged at 1500 $\mathrm{g}$ for 10 minutes at $4^{\circ} \mathrm{C}$. The supernatant was removed and centrifuged at $10,000 \mathrm{~g}$ for 15 minutes at $4^{\circ} \mathrm{C}$. The supernatant was removed and stored at $-80^{\circ} \mathrm{C}$ as the cytosolic fraction. The pellet containing the mitochondrially enriched fraction was washed twice in $20 \mathrm{mM}$ phosphate buffered saline (PBS) $\mathrm{pH}$ 7.4. The mitochondria were then lysed in mitochondrial lysis buffer $(50 \mathrm{mM}$ Tris, $7 \mathrm{M}$ urea, $3 \%$ CHAPS with protease inhibitors) for 20 minutes at room temperature. The mitochondrial lysate was centrifuged at $10,000 \mathrm{~g}$ for 10 minutes at $4^{\circ} \mathrm{C}$. A modified Lowry protein assay was used to determine the protein concentration. All samples were stored at $-80^{\circ} \mathrm{C}$ until further analysis.

\section{Subcellular fractionation of fresh brain tissue}

Brains were removed immediately from killed mice, weighed (around $300 \mathrm{mg}$ ) and immersed in ice cold mitochondria isolating buffer (MIB) $(0.25 \mathrm{M}$ sucrose, 0.5 $\mathrm{mM}$ potassium EDTA, $10 \mathrm{mM}$ Tris- $\mathrm{HCl} \mathrm{pH}$ 7.4). All glassware and equipment was kept cold $\left(4^{\circ} \mathrm{C}\right)$. The brain tissue was homogenized in $4.0 \mathrm{~mL}$ of $12 \%$ percoll in MIB, with a Dounce homogenizer with 30 strokes. The homogenate $(\sim 3.5 \mathrm{~mL})$ was then layered onto a previously poured $3.5 \mathrm{~mL} 26 \%$ percoll which itself had been poured over $3.5 \mathrm{~mL}$ of $40 \%$ percoll. The sample was centrifuged at $30,000 \mathrm{~g}$ for 1 minutes at $4^{\circ} \mathrm{C}$. The top layer containing myelin and other cellular debris was carefully removed using a Pasteur pipette and discarded. The second layer containing the mitochondria was carefully removed and diluted 1:4 in cold MIB and centrifuge at $15,000 \mathrm{~g}$ for 10 minutes at $4^{\circ} \mathrm{C}$. The resulting pellet was resuspended with $1 \mathrm{~mL} \mathrm{MIB}$ and centrifuged once more at $15,000 \mathrm{~g}$ for 10 minutes. The pellet was then vortexed in mitochondria lysis buffer for 1 minute and incubated for 20 minutes at room temperature. The lysate was centrifuged at $10,000 \mathrm{~g}$ for 10 minutes at $4^{\circ} \mathrm{C}$. The supernatant protein concentration was determined and the samples were stored at $-80^{\circ} \mathrm{C}$ until further analysis.

\section{Ion exchange fractionation}

Cytosolic and mitochondrially enriched fractions were further fractionated using ion exchange chromatography in a spin column format (UFC30HV00 column, UFC 3000 TB centrifuge tube, Millipore, Billerica, MA). Samples $(100 \mu \mathrm{g}$ each) were equilibrated with $50 \mu \mathrm{l}$ of buffer A (9 M Urea, 2\% CHAPS in $50 \mathrm{mM}$ Tris $\mathrm{HCl} \mathrm{pH} \mathrm{9.0)}$ for 20 minutes at room temperature. Buffer B (buffer A diluted 1 part to 8 parts with $50 \mathrm{mM}$ Tris $\mathrm{HCl}, \mathrm{pH} 9.0$ ) was used to dilute samples to $200 \mu \mathrm{L}$. The quaternary ammonium anion exchange beads (Q ceramic HyperD F, Pall BioSera, New York, NY) were equilibrated with three changes of $200 \mu \mathrm{L}$ of buffer B. Samples were loaded onto the column and mixed on an end-to-end mixer for 30 minutes at room temperature. Samples were centrifuged for 1 minute at $1000 \mathrm{~g}$. This eluate was the flow-through fraction. The column was removed from the centrifuge tube and placed in the next centrifuge tube (Q1, pH 9). $400 \mu \mathrm{L}$ of $\mathrm{pH} 9$ elution buffer (50 mM Tris $\mathrm{HCl} \mathrm{pH} \mathrm{9.0,} \mathrm{0.1} \mathrm{OGP)} \mathrm{was} \mathrm{loaded} \mathrm{onto} \mathrm{the}$ column and placed on the end-to-end mixer for 10 
minutes and then centrifuged. This process was repeated for fraction Q2 (pH 7.0 elution buffer: 50 mM HEPES $\mathrm{pH}$ 7.0, 0.1\% OGP), fraction Q3 ( $\mathrm{pH} 5.0$ elution buffer: $100 \mathrm{mM}$ sodium acetate $\mathrm{pH}$ 5.0, 0.1\% OGP), fraction Q4 ( $\mathrm{pH} 4.0$ elution buffer: $100 \mathrm{mM}$ sodium acetate $\mathrm{pH} 4.0$, 0.1\% OGP), fraction Q5 (pH 3.0 elution buffer: $50 \mathrm{mM}$ sodium acetate $\mathrm{pH} 3.0,0.1 \%$ OGP), and fraction Q6 (organic wash: 33\% isopropanol, 17\% acetonitrile and $0.1 \%$ trifluroacetic acid). All fractions were stored at $-80^{\circ} \mathrm{C}$ until use. Three fractions (Q1, Q2, and Q4) derived from the cytosolic fraction of pooled control mice brains were employed for the reproducibility study. The EAE study employed mitochondrial fractions (Q1- Q6), from individual EAE and control mice.

\section{ProteinChip array preparation}

The samples obtained from ion exchange fractionation were analyzed using NP20 ProteinChip arrays (Cipher gen Biosystems, Fremont, CA). Each ProteinChip was prepared according to the Ciphergen ProteinChip Application guide (ProteinChip Applications Guide Volume 2 ). Briefly, $1 \mu \mathrm{L}$ of each sample was applied directly to the ProteinChip array in a randomized manner. After air-drying for 3 minutes, all spots were treated with $1 \mu \mathrm{L}$ applications of matrix (saturated sinapinic acid (SPA) in $0.5 \%$ trifluoroacetic acid, $50 \%$ acetonitrile) letting the spots dry between each application.

\section{Data acquisition and processing}

Mass spectra were acquired using a model PBSIIc SELDI-TOF-MS (Ciphergen Biosystems, Fremont, CA). SELDI mass spectra were acquired with a laser intensity of 225 and a detector sensitivity of 8 for high molecular weight proteins (HMW protocol), and a laser intensity of 199 and a detector sensitivity of 9 for low molecular weight proteins (LMW protocol). Both high and low molecular weight spectra were acquired at a digitizer rate of $250 \mathrm{MHz}$ in positive ion mode with a chamber vacuum of less than $5 \times 10^{-7}$ torr, a source voltage of 20 $\mathrm{kV}$ and a detector voltage of 2,700 V. A total of 65 transients were averaged for each spectrum. Spectral processing (smoothing and baseline subtraction) was performed with ProteinChip 3.1 software. All spectra were calibrated externally using an All-in-1 peptide standard [porcine dynorphin, 2147.50 Da; bovine insulin $\beta$-chain, 3495.94 Da; and hirudin BHVK, 7033.61 Da], and an All-in-1 protein standard [bovine cytochrome c, $12230 \mathrm{Da}$; bovine carbonic anhydrase, $29024 \mathrm{kDa}$; and S. cerevisiae enolase, $46670 \mathrm{Da}$ ] (Ciphergen Biosystems, Fremont, CA). Peak intensities were normalized against the total ion current (TIC), excluding the mass range below $1500 \mathrm{Da}$, which is composed of strong signals from the SPA matrix. Because automatic peak selection by the Ciphergen Express software can miss features that appear as shoulders on large peaks, all spectra were subjected to manual peak-picking. All peaks that are present in at least $25 \%$ of the spectra and with SNR $\geq 3$ were selected.

\section{Data analysis}

Univariate (Mann-Whitney test) and multivariate statistical analysis (principal component analysis (PCA)) were performed using Ciphergen Express software. Analysis of variance (ANOVA) was employed to calculate the $\mathrm{p}$-value. SELDI-MS peak intensity differences were considered significant when $\mathrm{p} \leq 0.05$. Hierarchical clustering was performed on all peaks that were present in at least $25 \%$ of spectra with SNR $>4.0$ and heat maps were generated [49].

\section{Protein purification}

For the EAE study, sample fractions containing differentially expressed proteins of interest were subjected to $1 \mathrm{D}$ electrophoresis on 16\% acrylamide Tris-glycine gels. Briefly, each sample was concentrated in a Thermo Speed Vac vacuum concentrator, then dissolved in sample buffer $(0.125 \mathrm{M}$ Tris- $\mathrm{HCl}, 4 \%$ SDS, $40 \%$ glycerol, $0.1 \%$ bromophenol blue, $\mathrm{pH} 6.8$, (Invitrogen)), followed by heating for 10 minutes at $75^{\circ} \mathrm{C} .20 \mathrm{uL}$ of sample mixture were loaded onto the appropriate lane in the gel and electrophoresed at 200Vfor 45 minutes. SeeBlue Plus2 (Invitrogen) pre-stained molecular weight standards were employed for calibration. The gel was stained with Coomassie Brilliant blue R 250 (0.25\% Commassie blue, $40 \%$ methanol, $7 \%$ acetic acid) and were destained with destaining solution I (40\% methanol, 7\% acetic acid) for one hour, and with destaining solution II (7\% acetic acid, 5\% methanol) overnight.

\section{In-gel digestion}

The desired protein bands were excised from the gel and subjected to in-gel trypsin digestion using a procedure employed at the Center for Proteomics and Bioinformatics, Case Western Reserve University. Gel plugs were covered with $25 \mathrm{mM}$ ammonium bicarbonate $(\mathrm{ABC})$ at room temperature for 10 minutes. The supernatant was replaced with $50 \%$ acetonitrile in $25 \mathrm{mM} \mathrm{ABC}$ for $10 \mathrm{mi}$ nutes. These first two steps were repeated twice. Gel plugs were then dried in a Thermo Speed Vac vacuum concentrator. $10 \mathrm{mM}$ dithiothreitol (DTT) in $25 \mathrm{mM} \mathrm{ABC}$ was added and the reaction allowed to proceed at $56^{\circ} \mathrm{C}$ for 45 minutes. The supernatant was then replaced with $55 \mathrm{~m} \mathrm{M}$ iodoacetamide and the reaction proceeded at room temperature in the dark for 45 minutes. Trypsin solution ( $2 \mathrm{ng} / \mu \mathrm{L}$ trypsin in $25 \mathrm{mM} \mathrm{ABC}$ ) was added and the digestion proceeded at $37^{\circ} \mathrm{C}$ overnight. Formic acid was used to quench the reaction. The digest solution containing the extracted peptides was stored at $-4^{\circ} \mathrm{C}$. 


\section{Peptide mass fingerprinting}

Proteins were identified by peptide mass fingerprinting and peptide sequencing using a Dionex Utimate 3000 capillary LC system on line with LTQ-Fourier Transform (FT) mass spectrometer (Thermo Electron Corp., Bremen, Germany) at the Center for Proteomics and Bioinformatics, Case Western Reserve University. The tandem mass spectra were annotated and peak list files were generated. The resulting peak list files were then used to interrogate sequences present in the indexed IPI mouse database with the Mascot algorithm (Matrix Science). A positive identification was accepted when a minimum of two peptide monoisotopic masses matched a particular protein with sequence coverage $\geq 10 \%$, and low expectation value $(\mathrm{p}<0.05)$.

\section{Western blotting}

Protein samples were mixed with SDS-PAGE sample buffer (Invitrogen) followed by heating at $70^{\circ} \mathrm{C}$ for 10 minutes. Protein samples were separated by SDS-PAGE on NuPage 4-12\% Bis-Tris mini gels (Invitogen) run at $200 \mathrm{~V}$ for 30 minutes, and then transferred to nitrocellulose paper at $45 \mathrm{~V}$ for 1 hour. The blot was blocked with $5 \%$ non-fat milk dissolved in $0.1 \%$ Tween-TBS buffer, and then incubated with antibody against Myelin Basic Protein overnight at $4^{\circ} \mathrm{C}$. The blot was washed with $0.1 \%$ Tween-TBS buffer and incubated with the secondary antibody conjugated with horseradish peroxidase (HRP) for 1 hour. The blot was washed with $0.1 \%$ Tween-TBS buffer and visualized using chemiluminescence reagent (sc2048, Santa Cruz Biotechnology, Inc., Santa Cruz, CA). Images were made by exposing X-ray film (Fuji Super RX) to the blots. The images were analyzed using Image J software (NIH, Bethesda, MD).

\section{Preparation and use of fluor-labeled MBP}

MBP was labeled with HiLyte Fluor 488 (Anaspec, Fremont, CA) according to the manufacturer's instructions. Briefly, $100 \mu \mathrm{g}$ of $\mathrm{MBP}$ was dialyzed overnight against $50 \mathrm{mM}$ PBS, pH 7.4 at $4^{\circ} \mathrm{C}$. Fluor was suspended in DMSO to generate $10 \mu \mathrm{L}$ of a $2 \mathrm{mM}$ solution. Protein labeling was conducted at a 7.5:1 ratio of fluor to protein at room temperature for 45 minutes. The dyeconjugated protein was washed with $50 \mathrm{mM}$ PBS, $\mathrm{pH}$ 7.4 and separated from unreacted dye by centrifugation in a spin column.

\section{Sample preparation}

Whole brains were harvested from euthanized pregnant wistar rats and stored at $-80^{\circ} \mathrm{C}$. Brains were homogenized in parallel with and without $500 \mu \mathrm{L}$ of fluorescent MBP added to $1.5 \mathrm{~mL}$ of general lysis buffer $(20 \mathrm{mM}$ $\mathrm{KCl}, 3 \mathrm{mM} \mathrm{MgCl} 2,10 \mathrm{mM}$ 4-(2-hydroxyethyl)1-piperazineethanesulfonic acid (HEPES) $\mathrm{pH}$ 7.9, 0.5\%
NP-40, 5\% glycerol with protease inhibitors (P2714, Sigma-Aldrich, St. Louis, MO using a Wheaton homogenizer with a Teflon ${ }^{\circ}$ pestle. in thirty strokes. The homogenate was centrifuged for 10 minutes at $500 \mathrm{~g}$ at $4^{\circ} \mathrm{C}$. The supernatant was removed and centrifuged at $10,000 \mathrm{~g}$ for 30 minutes at $4^{\circ} \mathrm{C}$. The pellet containing the mitochondrially enriched fractions was further purified by washing once in $20 \mathrm{mM}$ phosphate buffered saline (PBS), $\mathrm{pH}$ 7.4. The mitochondrial fractions were stored at $4^{\circ} \mathrm{C}$.

\section{Fluorescent spectroscopy}

Emission spectra were acquired on a Cary Eclipse spectrofluorimeter. The fluorescence intensity at $523 \mathrm{~nm}$ was employed to compare the levels of fluor-labelled MBP observed in each sub-cellular fraction.

\section{Ethical approval}

All mice, from which EAE and control brain tissue was obtained, were handled in accordance with the policies outlined by the Canadian Council for Animal Care and the University of Calgary. All other animals were handled according to guidelines of the Institutional Animal Care and Use Committee at Kent State University outlined in protocols 338 and 350.

\section{Competing interests}

The authors declare no competing interests.

\section{Authors' contributions}

SA collected and analyzed the data for the SELDI-MS reproducibility study and EAE protein profile study and contributed to the interpretation of the results and the writing; LB performed the fluorescence studies of MBP contamination, SL performed the Western blot analysis of MBP contamination in fresh and frozen tissue, EF and JM contributed to the study design and the interpretation of the results, RBG contributed to the study design, interpretation of the results and the writing. All authors read and approved the final manuscript.

\section{Acknowledgements}

We are grateful to Dr. Wee Yong, Department of Clinical Neurosciences and Oncology, University of Calgary for providing brain tissue from EAE mice. This research was funded by NIH Grant R21NS058921 (JM).

\section{Author details}

${ }^{1}$ Department of Chemistry and Biochemistry, Kent State University, Kent, Ohio 44242, USA. ${ }^{2}$ Department of Biological Sciences, Kent State University, Kent, Ohio 44242, USA.

Received: 24 October 2012 Accepted: 25 March 2013

Published: 1 May 2013

\section{References}

1. Compston A, Coles A: Multiple Sclerosis. Lancet 2008, 372:1502-1517.

2. Mix E, Pahnke J, Ibrahim S: Gene-expression profiling of experimental autoimmune encephalomyelitis. Neurochem Res 2002, 27:1157-63.

3. Steinman L, Zamvil S: How to successfully apply animal studies in experimental allergic encephalomyelitis to research on multiple sclerosis. Ann Neurol 2006, 60:12-21.

4. Constantinescu C, Farooqi N, O'Brien K, Gran B: Experimental autoimmune encephalomyelitis (EAE) as a model for multiple sclerosis. Brit J Pharm 2011, 164:1079-1106. 
5. Cook S: Handbook of Multiple Sclerosis. 4th edition. New York: Taylor \& Francis; 2006.

6. Martin R, McFarland $\mathrm{H}$ : Immunological aspects of experimental allergic encephalomyelitis and multiple sclerosis. Crit Rev Clin Lab Sci 1995 32:121-82.

7. Friese M, Montalban X, Willcox N, Bell J, Martin R, Fugger L: The value of animal models for drug development in multiple sclerosis. Brain 2006, 129:1940-52.

8. Majewska M, Zajac K, Srebro Z, Sura P, Ksiazek L, Zemelka M, Szczepanik M: Epicutaneous immunization with myelin basic protein protects from the experimental autoimmune encephalomyelitis. Pharmacol Rep 2007, 59:74-9.

9. Ballinger S: Mitochondrial dysfunction in cardiovascular disease. Free Radical Biol Med 2005, 38:1278-1295.

10. Trushina E, McMurray C: Oxidative stress and mitochondrial dysfunction in neurodegenerative diseases. Neuroscience 2007, 145:1233-1248.

11. Navarro A, Boveris A: Brain mitochondrial dysfunction in aging, neurodegeneration, and Parkinson's disease. Front Aging Neurosci 2010, 2:34

12. Jiang $Y$, Wang $X$ : Comparative mitochondrial proteomics: perspective in human diseases. J Hemtology Oncolology 2012, 5:11.

13. Inglese $\mathrm{M}, \mathrm{Ge} Y$, Filippi M, Falini A, Grossman $\mathrm{R}$, Gonen O: Indirect evidence for early widespread gray matter involvement in relapsing-remitting multiple sclerosis. Neuroimage 2004, 21:1825-182.

14. Cader S, Johansen-Berg H, Wylezinska M, Palace J, Behrens T, Smith S, Matthews P: Discordant white matter $\mathrm{N}$-acetylaspartate and diffusion MRI measures suggest that chronic dysfunction contributes to axonal pathology inmultiple sclerosis. Neuroimage 2007, 36:19-27.

15. Forte M, Gold B, Marracci G, Chaudhary P, Basso E, Johnsen D, Yu X, Fowlkes J, Rahder M, Stem K, Bernardi P, Bourdette D: Cyclophilin D inactivation protects axons in experimental autoimmune encephalomyelitis, an animal model of multiple sclerosis. Proc Natl Acad Sci USA 2007, 104:7558-7563.

16. Mronga T, Stahnke T, Goldbaum O, Richter-Landsberg C: Mitochondrial pathway is involved in hydrogen-peroxide-induced apoptotic cell death of oligodendrocytes. Glia 2004, 46:446-455.

17. Ghafourifar P, Mousavizadeh K, Parihar M, Nazarewicz R, Parihar A, Zenebe W: Mitochondria in multiple sclerosis. Front Biosci 2008, 13:3116-3126.

18. Mahad D, Ziabreva I, Lassman H, Turnbull D: Mitochondrial defects in acute multiple sclerosis lesions. Brain 2008, 131:1722-1735.

19. Kalman B, Laitinen K, Komoly S: The involvement of mitochondria in the pathogenesis of multiple sclerosis. J Neuroimmunol 2007, 188:1-12.

20. Witte ME, BØL, Rodenburg R, Belien A, Musters R, Hazes T, Wintjes L, Smeitink J, Geurts J, De Vries H, van der Valk P, Van Horssen J: Enhanced number and activity of mitochondria in multiple sclerosis lesions. J Pathol 2009, 219:193-204.

21. Pandit A, Vadnal J, Houston S, Freeman E, McDonough J: Impaired regulation of electron transport chain subunit genes by nuclear respiratory factor 2 in multiple sclerosis. J Neurol Sci 2009, 279:14-20.

22. Dutta R, McDonough J, Yin X, Peterson J, Chang A, Torres T, Gudz T, Macklin B, Lewis A, Fox J, Rudick R, Mirnics K, Trapp D: Mitochondrial dysfunction as a cause of axonal degeneration in multiple sclerosis patients. Ann Neurol 2006, 59:478-489.

23. Sowell A, Owen J, Butterfield A: Proteomics in animal models of Alzheimer's and Parkinson's diseases. Ageing Res Rev 2009, 8:1-17.

24. Zhang J, Keene D, Pan C, Montine S, Montine J: Proteomics of human neurodegenerative diseases. J Neuropathol Exp Neurol 2008, 67:923-32.

25. Han H, Hwang I, Roy B, Lundgren H, Price V, Ousman S, Fernald G, Gerlitz B, Robinson H, Baranzini E, Grinnell W, Raine S, Sobel A, Han K, Steinman L: Proteomic analysis of active multiple sclerosis lesions reveals therapeutic targets. Nature 2008, 451:1076-81.

26. Elkabes S, Li H: Proteomic strategies in multiple sclerosis and its animal models. Proteomics Clin App/ 2007, 1(11):1393-1405.

27. Dumont D, Noben P, Raus J, Stinissen P, Robben J: Proteomic analysis of cerebrospinal fluid from multiple sclerosis patients. Proteomics 2004, 4:2117-24.

28. Rithidech N, Honikel L, Milazzo M, Madigan D, Troxell R, Krupp B: Protein expression profiles in pediatric multiple sclerosis: potential biomarkers. Mult Scler 2009, 15:455-64.

29. Linker A, Brechlin P, Jesse $S$, Steinacker $P$, Lee $H$, Asif R, Jahn O, Tumani $H$, Gold R, Otto M: Proteome profiling in murine models of multiple sclerosis: Identification of stage specific markers and culprits for tissue damage. PLoS One 2009, 4(10):e7624.
30. Fazeli S, Nasrabadi D, Sanati H, Pouya A, Ibrahim M, Baharvand H, Salekdeh $\mathrm{H}$ : Proteome analysis of brain in murine experimental autoimmune encephalomyelitis. Proteomics 2010, 10:2822-2832

31. Broadwater L, Pandit A, Azzam S, Clements R, Vadnal J, Sulak M, Yong W, Freeman J, Gregory R, McDonough J: Analysis of the mitochondrial proteome in multiple sclerosis cortex. Biochim Biophys Acta 1812, 2011:630-641.

32. Rosenling T, Attali A, Luider M, Bischoff R: The experimental autoimmune encephalomyelitis model for proteomic biomarker studies: From rat to human. Cinica Chimica Acta 2011, 412:812-822.

33. Farias A, Martins-de-Souza D, Guimaraes L, Pradella F, Moraes A, Facchini G, Novello J, Santos L: Proteome analysis of spinal cord during the clinical course of monophasic experimental autoimmune encephalomyelitis. Proteomics 2012, 12:2656-2662.

34. Timms J, Cramer R: Difference Gel Electrophoresis. Proteomics 2008 8:4886-4897.

35. Minden J, Dowd S, Meyer H, Stuhler K: Difference Gel Electrophoresis. Electrophoresis 2009, 30:S156-S161.

36. Chevalier F: Highlights on the Capacities of "Gel-based" Proteomics. Proteome Science 2010, 8:23-32.

37. Wang G, Wu W, Zeng W, Chou L, Shen F: Label-Free Protein Quantification Using LC-Coupled Ion Trap or FT Mass Spectrometry: Reproducibility, Linearity, and Application with Complex Proteomes. J Proteome Res 2006, 5:1214-1223.

38. Gygi P, Rist B, Gerber A, Turecek F, Gelb H, Abersold R: Quantitative Analysis of Complex Protein Mixtures using Isotope-coded Affinity Tags. Nature Biotech 1999, 17:994-999.

39. Wiese S, Reidegeld A, Meyer E, Warscheid B: Protein Labeling by iTRAQ: A New Tool for Quantitative Mass Spectrometry in Proteome Research. Proteomics 2007, 7:340-350.

40. Elliott H, Smith S, Parker E, Borchers C: Current trends in Quantitative Proteomics. J Mass Spec 2009, 44:1637-1660.

41. Hutchens W, Yip T: New Desorption Strategies for the Mass Spectrometric Analysis of Macromolecules. Rapid Commun Mass Spectrom 1993, 7:576-580

42. Issaq J, Conrads P, Prieto A, Tirumalai R, Veenstra D: SELDI -TOF-MS for Diagnostic Proteomics. Analyt Chem 2003, 75:149 A-155A

43. Wei W, Martin A, Johnson J, Ward G: 10 Years of SELDI: What have we Learnt? Current Proteomics 2010, 7:15-25.

44. Poon W: Opportunities and Limitations of SELDI-TOF-MS in Biomedical Research: Practical Advice. Expert Rev Proteomics 2007, 4:51-65.

45. Woolley F, Al-Rubeai M: The Application of SELDI-TOF Mass Spectrometry to Mammalian Cell Culture. Biotech Advances 2009, 27:177-184.

46. Jackson E: A User's Guide to Principal Components. Statistics: Wiley Series in Probability and; 2003.

47. Shlens J: A tutorial on Principal Components Analysis. 2009. Version 3.01, http://www.snl.salk.edu/ shlens/pca.pdf.

48. Yeung K, Ruzzo W: Principal component analysis for clustering gene expression data. Bioinformatics 2001, 17:763-774.

49. Eisen B, Spellman T, Brown O, Botstein D: Cluster analysis and display of genome-wide expression patterns. Proc Natl Acad Sci USA 1998, 95:14863-8.

50. Seno S, Teramoto R, Takenaka $Y$, Matsuda $\mathrm{H}$ : A method for clustering gene expression data based on graph structure. Genome Inform 2004, 15:151-60.

51. Katz-Jaffe G, Gardner K, Schoolcraft B: Proteomic analysis of individual human embryos to identify novel biomarkers of development and viability. Fertil Steril 2006, 85:101-7.

52. Hong H, Dragan Y, Epstein J, Teitel C, Chen B, Xie Q, Fang H, Shi L, Perkins $\mathrm{R}$, Tong W: Quality control and quality assessment of data from surfaceenhanced laser desorption/ionization (SELDI) time-of flight (TOF) mass spectrometry (MS). BMC Bioinforma 2005, 6:S5

53. Semmes J, Cazares H, Ward D, Ward D, Qi L, Moody M, Maloney E, Morris J, Trosset W, Hisada M, Gygi S, Jacobson S: Discrete serum protein signatures discriminate between human retrovirus associated hematologic and neurologic disease. Leukemia 2005, 19:1229-38.

54. Diao L, Clarke H, Coombes R, Hamilton R, Roth J, Mao L, Czerniak B, Baggerly A, Morris S, Fung T, Bast G: Reproducibility of SELDI Spectra Across Time and Laboratories. Cancer Informatics 2011, 10:45-64.

55. Selvaraju S, El Rassi Z: Liquid-phase-based separation systems for depletion, prefractionation and enrichment of proteins in biological fluids and matrices for in-depth proteomics analysis-An update covering the period 2008-2011. Electrophoresis 2012, 33:74-88. 
56. De Bock M, de Seny D, Meuwis A, Servais C, Minh Q, Closset J, Chapelle J, Louis E, Malaise M, Merville P, Fillet M: Comparison of three methods for fractionation and enrichment of low molecular weight proteins for SELDI-TOF-MS differential analysis. Talanta 2010, 82:245-254.

57. Lavine B, Workman J: Chemometrics. Anal Chem 2010, 82:4699-4711.

58. Mao P, Reddy $\mathrm{H}$ : Is multiple sclerosis a mitochondrial disease? BBA Mol Basis Dis 1802, 2010:66-79.

59. Qi X, Lewin S, Sun L, Hauswirth W, Guy J: Mitochondrial protein nitration primes neurodegeneration in experimental autoimmune encephalomyelitis. J Biol Chem 2006, 281:31950-31962.

60. Ravera S, Panfoli I, Calzia D, Aluigi G, Bianchini P, Diaspro A, Mancardi G, Morelli A: Evidence for aerobic ATP synthesis in isolated myelin vesicles. Int J Biochem Cell Bio 2009, 41:1581-1591.

61. Stahl L, Swanson D: Effects of freezing and storage on subcellular fractionation of guinea pig and human brain. Neurobiology 1975, 5:393-400.

62. Ottens K, Golden C, Bustamante L, Hayes L, Denslow D, Wang K: Proteolysis of multiple myelin basic protein isoforms after neurotrauma: characterization by mass spectrometry. J Neurochem 2008, 104:1404-14.

63. Shiryaev A, Savinov Y, Cieplak P, Ratnikov I, Motamedchaboki K, Smith W, Strongin Y: Matrix Metalloproteinase Proteolysis of the Myelin Basic Protein Isoforms Is a Source of Immunogenic Peptides in Autoimmune Multiple Sclerosis. PLoS One 2009, 4:e4952.

64. Schaecher E, Shields C, Banik L: Mechanism of myelin breakdown in experimental demyelination: a putative role for calpain. Neurochem Res 2001, 26:731-7.

65. Liu C, Akle V, Zheng W, Kitlen J, O'Steen B, Larner F, Dave R, Tortella C, Hayes L, Wang K: Extensive degradation of myelin basic protein isoforms by calpain following traumatic brain injury. J Neurochem 2006, 98:700-12.

66. Medveczky P, Antal J, Patthy A, Kékesi K, Juhász G, Szilágyi L, Gráf L: Myelin basic protein, an autoantigen in multiple sclerosis, is selectively processed by human trypsin 4. FEBS Lett 2006, 580:545-552.

67. Dasilva $G$, Yong W: Expression and regulation of matrix metalloproteinase-12 in experimental autoimmune encephalomyelitis and by bone marrow derived macrophages in vitro. J Neuroimmunol 2008, 199:24-34

\section{doi:10.1186/1477-5956-11-19}

Cite this article as: Azzam et al:: A SELDI mass spectrometry study of experimental autoimmune encephalomyelitis: sample preparation, reproducibility, and differential protein expression patterns. Proteome Science 2013 11:19.

\section{Submit your next manuscript to BioMed Central and take full advantage of:}

- Convenient online submission

- Thorough peer review

- No space constraints or color figure charges

- Immediate publication on acceptance

- Inclusion in PubMed, CAS, Scopus and Google Scholar

- Research which is freely available for redistribution 